\title{
Eucalyptus ESTs corresponding to the protoporphyrinogen IX oxidase enzyme related to the synthesis of heme, chlorophyll, and to the action of herbicides
}

\author{
Edivaldo Domingues Velini ${ }^{1}$, Maria Lúcia Bueno Trindade ${ }^{1}$, Elza Alves ${ }^{1}$, Ana Catarina Catâneo ${ }^{2}$, \\ Celso Luis Marino ${ }^{3}$, Ivan de Godoy Maia ${ }^{3}$, Edson Seizo Mori ${ }^{4}$,Edson Luiz Furtado, \\ Iraê Amaral Guerrini ${ }^{6 \#}$, Carlos Frederico Wilcken ${ }^{7}$
}

${ }^{1}$ Universidade Estadual Paulista "Júlio de Mesquita Filho”, Faculdade de Ciências Agrárias, Fazenda Experimental Lageado, Laboratório de Matologia, Botucatu, SP, Brazil.

${ }^{2}$ Universidade Estadual Paulista "Júlio de Mesquita Filho”, Instituto de Biociências,

Laboratório de Xenobióticos, Botucatu, SP, Brazil.

${ }^{3}$ Universidade Estadual Paulista "Júlio de Mesquita Filho”, Instituto de Biociências,

Laboratório de Genética, Botucatu, SP, Brazil.

${ }^{4}$ Universidade Estadual Paulista "Júlio de Mesquita Filho", Faculdade de Ciências Agrárias, Fazenda Experimental Lageado, Laboratório de Melhoramento Vegetal, Botucatu, SP, Brazil.

${ }^{5}$ Universidade Estadual Paulista "Júlio de Mesquita Filho", Faculdade de Ciências Agrárias, Fazenda Experimental Lageado, Laboratório de Fitopatologia, Botucatu, SP, Brazil.

"Universidade Estadual Paulista "Júlio de Mesquita Filho", Faculdade de Ciências Agrárias, Fazenda Experimental Lageado, Laboratório de Solos, Botucatu, SP, Brazil.

${ }^{7}$ Universidade Estadual Paulista "Júlio de Mesquita Filho", Faculdade de Ciências Agrárias, Fazenda Experimental Lageado, Laboratório de Entomologia, Botucatu, SP, Brazil.

\begin{abstract}
This work was aimed at locating Eucalyptus ESTs corresponding to the PROTOX or PPO enzyme (Protoporphyrinogen IX oxidase, E.C. 1.3.3.4) directly related to resistance to herbicides that promote oxidative stress, changing the functionality of this enzyme. PROTOX, which is the site of action of diphenyl-ether (oxyfluorfen, lactofen, fomesafen), oxadiazole (oxadiazon and oxadiargyl), and aryl triazolinone (sulfentrazone and carfentrazone) herbicides, acts on the synthesis route of porphyrins which is associated with the production of chlorophyll a, catalases, and peroxidases. One cluster and one single read were located, with e-values better than e-70, associated to PROTOX. The alignment results between amino acid sequences indicated that this enzyme is adequately represented in the ESTs database of the FORESTs project.
\end{abstract}

Key words: Eucalyptus, protoporphyrinogen IX oxidase, catalase, peroxidase, herbicide.

Received: Mau 28, 2004; Accepted: June 6, 2005.

\section{Introduction}

The protoporphyrinogen IX oxidase enzyme, known as Protox or PPO, corresponds to the site of action of several herbicides from different chemical groups. The herbicide action is implicated in promoting oxidative stress by

Send correspondence to Edivaldo Domingues Velini. Universidade Estadual Paulista, Faculdade de Ciências Agrárias, Fazenda Experimental Lageado, Laboratório de Matologia, 18603-970 Botucatu, SP, Brazil. E-mail: velini@fca.unesp.br. \#Supported by CNPq. producing free radicals. There exist three other mechanisms of action also related to oxidative stress: interference with the electron flow in the Photosystem I (diquat and paraquat), interference with the electron flow in the Photosystem II, more specifically with the D1QB complex (triazines, triazinones, chloroanilides, ureas and uracils), and glutamine synthetase inhibition (glufosinate).

Variability in the levels of action of the herbicides that act upon these sites primarily depends on characteristics of the site itself (amino acids sequence in the proteins and expression levels), as well as the plants ability to inacti- 
vate free radicals produced, which actually generate plant intoxication. Variability in absorption and translocation capacity (even at small distances) is also an important factor that conditions the effectiveness of any compound with herbicidal action.

Tetrapyrrole biosynthesis is important in plants because it provides to many essential molecules involved in light harvesting, energy transfer, signal transduction, detoxification, and systemic acquired resistance (Wettstein et al., 1995; Grimm, 1998; Molina et al., 1999). The most abundant tetrapyrroles are chlorophyll and heme, which are important compounds for photosynthesis and respiration. Protoporphyrinogen IX oxidase (Protox, EC 1.3.3.4) is the last enzyme in the common pathway of chlorophyll and heme biosynthesis (Beale and Weinstein, 1990). Protox catalyzes the oxidative $\mathrm{O}_{2}$-dependent aromatization of the colorless protoporphyrinogen IX to the highly conjugated protoporphyrin IX.

In this work, only ESTs related to the Protox enzyme will be addressed. Protox is a key enzyme for the production of porphyrins and chlorophylls in plants, and a site of action for several compounds with herbicidal activity (Figure 1). The study of ESTs related to detoxifying systems, which are important to define the levels of action of herbicides that cause oxidative stress, was already carried out by Alves et al. (2005).

This mechanism of action of herbicides and the compounds that act upon it have been presented in detail by Dodge (1992), Hess (1993), and Weller (2002). Inhibition of protoporphyrin IX synthesis by herbicides generates an intriguing accumulation of this pigment in plants. Protoporphyrin IX is an extremely reactive molecule which, in the presence of light and Oxygen, produces singlet Oxygen,

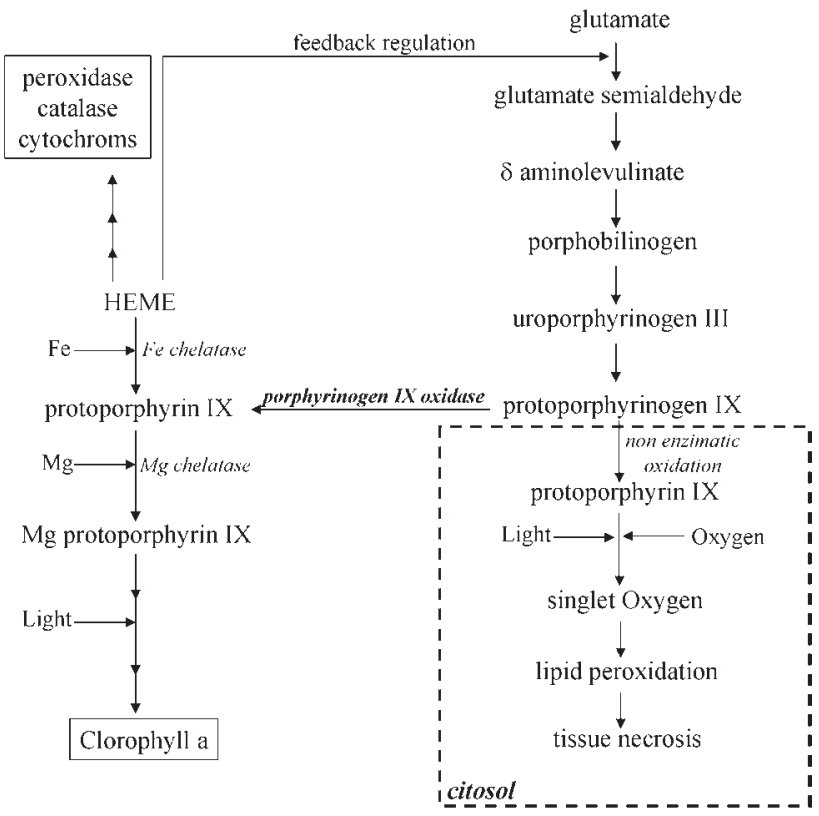

Figure 1 - Synthesis route of porphyrins in plants (adapted from Dodge, 1991; Hess, 1993; Nelson and Leningher, 2000; Weller, 2002). a free radicals with a high lipid oxidation capacity (Figure 1). This fluorescent pigment is intensely produced in the chloroplasts by the action of Protox, from protoporphyrinogen IX. Since route regulation depends on the production of protoporphyrin IX inside organelles, inhibiting the activity of this enzyme in chloroplasts generates great protoporphyrinogen IX accumulation, which is released into the cytosol. Once in the cytosol, the protoporphyrinogen IX is non-enzymatically converted into protoporphyrin IX, which is accumulated at high concentrations (hundreds of times higher than normal). In contact with light, this pigment produces a great amount of free radicals which quickly burst the cell membranes, causing the death of tissues and plants.

Watanabe et al. (2001) discuss in detail the action and codification of Protox, crucial for heme and chlorophyll production. This enzyme is present and acts on the chloroplasts (producing chlorophyll) and mitochondria (producing heme), but is entirely codified in the nucleus. The authors also studied and demonstrated the existence of intracellular translocation of Protoporphyrinogen and Protoporphyrin IX. The results indicated that the excess of these compounds present in the chloroplasts and cytosol, as a consequence of the sub-lethal action of herbicides, could be used in the mitochondria to produce heme groups, which are essential for the formation of catalases and peroxidases.

Catalases and peroxidases are important in the reduction of stresses of different origins, because they are important free radical inactivators (Chaudière and Ferrari-Iliou, 1999). Thus, raising the amount or activity of Protox could be an important tool to increase photosynthetic efficiency (related to the chlorophyll a content), or to increase tolerance to herbicides and stresses of an environmental (especially nutritional, thermal, and hydric) or biological nature (associated with pests, diseases, and weeds).

It must be highlighted that the toxic action of herbicides is exclusively associated with the interaction with Protox from chloroplasts. Oxyfluorfen is the main selective herbicide in eucalyptus, and is largely used in conventional planting areas, being overtop applied after seedling transplantation. Sulfentrazone, which has been recently registered in Brazil, is applied on the same way and shows great potential for use in Eucalyptus because of its broad control spectrum, selectivity to several clones, long residual effect and high solubility, witch makes possible the transposition through the litterfall with rain water and allows sulfentrazone to be used in reduced tillage areas. Rodrigues and Almeida (1998) presented the conditions of use of these herbicides in foresting areas.

Both oxyfluorfen and sulfentrazone can intoxicate Eucalyptus, mainly when the herbicides are not applied immediately after transplanting. The young leaves that are formed between planting and the application show greater 
sensitivity to the compounds, and can present quite pronounced injuries.

Considering the information here presented, the synthesis route of protoporphyrin could be altered with two objectives: a) tolerance to herbicides and production of chlorophylls, related to chloroplast forms of prototoporphyrinogen IX osidase; b) production of heme in association with the synthesis of cytochrome a, cytochrome c, catalase and peroxidase enzymes, related to mitochondria forms of Protox.

Considering tolerance to herbicides, locating different configurations of the enzyme or promoters that would condition different levels of expression could allow genotypes more tolerant to the mentioned herbicides to be obtained. Their evaluation can be done through the application of normal rates of herbicides followed by injury evaluation, or by applying low rates and monitoring the concentrations of intermediate and final products of the route.

With respect to the production of cytochromes, catalases and peroxidases, the lack of some information about the enzyme systems that operate in mitochondria makes the most suitable procedure to consist in the identification of genotypes with the highest concentrations or levels of activity of these enzymes. Evaluating the concentrations of intermediate products is essential to determine which points in the route (enzymes) will be surely critical for genotype discrimination. The greatest information gap corresponds to the lack of sequencings of the mitochondrial form of the enzyme. The paper by Watanabe et al. (2001) is an exception. The authors isolated and sequenced spinach Protox cDNA which encodes a homologue of tobacco mitochondrial Protox II. Immunoblot analysis of spinach leaf extract detected two proteins with apparent molecular masses of 57 an $55 \mathrm{kDa}$ in chloroplasts and mitochondria, respectively. In vitro translation experiments indicated that two translation products (59 and $55 \mathrm{kDa}$ ) are produced from Protox II mRNA, using two in-frame initiation codons. Transport experiments using green fluorescent protein-fused Protox II suggested that the larger and smaller translation products target exclusively to chloroplasts and mitochondria, respectively.

This work was aimed at locating Eucalyptus ESTs corresponding to the protoporphyrinogen IX oxidase enzyme (PROTOX or PPO; E.C. 1.3.3.4) directly related to the action of several herbicides and involved in the production of chlorophyll and heme.

\section{Material and Methods}

This work resulted from an analysis of the information bank produced in the first stage of the Eucalyptus Genome Project (Projeto Genoma do Eucalyptus - FORESTs), jointly developed by FAPESP and a consortium of four companies in the forestry industry (Duratex, Ripasa, Suzano, and VCP) and executed with the participation of 20 laboratories from the State of São Paulo associated with the AEG network (https:forests.esalq.usp.br). In all, 123,889 reads constructed from expressed sequence tags (ESTs) of cDNA libraries, mainly derived from Eucalyptus grandis tissues, were obtained. The tissues were removed from different organs of plants submitted to different growing conditions. The makeup and coding of the libraries are described in Table 1.

The search for enzyme sequences corresponding to PROTOX was performed using the BLAST tool (Altschud et al., 1997). The amino acid sequences for those enzymes, described for different plant species, were compared with the information from the FORESTs project database using the "tBLASTn" option, allowing the identification of Clusters associated with them. Only Clusters adequately aligned with the amino acid sequences were selected, using an e-value $<\mathrm{e}-70$ as a selection criterion. The Clusters that best aligned with sequences obtained from the literature were chosen for the next step.

The nucleotide sequences of the selected Clusters were compared with the NCBI (National Center Biotechnology Information) and the geneBank amino acid sequence databases after translation in all possible frames. The procedure allowed to confirm the alignment with sequences of the enzyme, to find the translation frame for the

Table 1 - Codes and source tissues of cDNA libraries approved by the FORESTS project.

\begin{tabular}{|c|c|}
\hline Code & Tissues / growing condition \\
\hline BK1 & $\begin{array}{l}\text { Bark, sapwood, heartwood, and pith of } 8 \text {-year old } E \text {. } \\
\text { grandis trees }\end{array}$ \\
\hline CL1 & E. grandis calluses formed in the dark \\
\hline CL2 & E. grandis calluses formed in the light \\
\hline FB1 & Buds, flowers and fruits \\
\hline LV1 & Seedling leaves \\
\hline LV2 & $\begin{array}{l}\text { Leaves from trees efficient and poorly efficient in } \\
\text { phosphorus and boron utilization }\end{array}$ \\
\hline LV3 & $\begin{array}{l}\text { Leaves colonized with the caterpillar Thyrinteina sp. for } \\
7 \text { days }\end{array}$ \\
\hline RT3 & Nursery seedling roots \\
\hline RT6 & Roots of trees resistant and susceptible to frost \\
\hline SL1 & $\begin{array}{l}\text { E. grandis seedlings grown in the dark and exposed to light } \\
\text { for } 3 \mathrm{~h} \text { prior to RNA extraction }\end{array}$ \\
\hline SL4 & E. globulus seedlings grown in the dark \\
\hline SL5 & E. saligna seedlings grown in the dark \\
\hline SL6 & E. urophylla seedlings grown in the dark \\
\hline SL7 & E. grandis seedlings grown in the dark \\
\hline SL8 & E. camaldulensis seedlings grown in the dark \\
\hline ST2 & $\begin{array}{l}\text { Stems of six-month old seedlings susceptible to water } \\
\text { deficit }\end{array}$ \\
\hline ST6 & Stems of seedlings susceptible to water deficit \\
\hline ST7 & Stems of trees resistant and susceptible to frost \\
\hline WD2 & E. grandis wood \\
\hline
\end{tabular}


cluster and to obtain values of identity percents and similarity probability values (e-value) for sequences from different plant species.

Based on the translation frame that produced the best alignments and using the software GENERUNR, the nucleotide sequence corresponding to the clusters was translated into amino acids for the identification and analysis of Open Read Frames. The amino acid sequences corresponding to ORFs were aligned with the amino acid sequences of different plant species (with e-value $<$ e-70 as previously described). The software CLUSTAL was used to align the sequences and to estimate the phylogenetic distances represented in consensus phylogenetic trees obtained from a total of 1,000 bootstrap trials. The trees were built up using the neighbor-joining method and were plotted with TreeView.

\section{Results and Discussion}

The PROTOX enzyme (Protoporphyrinogen IX oxidase) is effectively represented in the FORESTs Sequence Database. Using the "tBLASTn" option in the BLAST tool, it was possible to identify two clusters with similarity indices (e-value) better than e-70 (Table 2).

The results of the alignments using nucleotide sequences of the clusters, translated into amino acid sequences in the different translation frames, with amino acid sequences available at the NCBI and the geneBank, are presented in Tables 3 and 4.

The cluster "EGCBSL4281G09.g" corresponds to a single read with 784 nucleotides. Frame +2 was used to translate the base sequences into amino acids. The start codon was located at positions 26 , and the nucleotide sequence was truncated by an end codon at the position 641 . Coding was obtained for a total of 205 amino acids. The alignment of the amino acid sequences from different species is represented in Figure 2. The sequence corresponding to the cluster "EGCBSL4281G09.g" aligned to the start region of the sequences from literature. If the same amino acid was observed in a certain position for all studied species, the column was marked with an asterisk enabling the
Table 2 - FORESTs clusters, identified through the tBlastn tool, which showed similarity with the PROTOX enzyme (protoporphyrinogen IX oxidase, E.C. 1.3.3.4)

\begin{tabular}{lccc}
\hline Species & Accession & Cluster & e-value \\
\hline Zea mays & CAD10611 & EGEQST1002B11.g & $3.00 \mathrm{E}-75$ \\
& & EGCBSL4281G09.g & $1.00 \mathrm{E}-70$ \\
Sorghum bicolor & CAD10608 & EGEQST1002B11.g & $3.00 \mathrm{E}-73$ \\
Oryza sativa & CAD10607 & EGEQST1002B11.g & $3.00 \mathrm{E}-75$ \\
Brassica napus & CAD10606 & EGCBSL4281G09.g & $5.00 \mathrm{E}-78$ \\
& & EGEQST1002B11.g & $5.00 \mathrm{E}-77$ \\
Beta vulgaris & CAD10605 & EGEQST1002B11.g & $8.00 \mathrm{E}-70$ \\
Gossypium & CAD10604 & EGCBSL4281G09.g & $2.00 \mathrm{E}-87$ \\
hirsutum & & EGEQST1002B11.g & $2.00 \mathrm{E}-85$ \\
Glycine Max & CAD10603 & EGEQST1002B11.g & $7.00 \mathrm{E}-81$ \\
& & EGCBSL4281G09.g & $7.00 \mathrm{E}-74$ \\
Triticum aestivum & CAD10602 & EGEQST1002B11.g & $6.00 \mathrm{E}-74$ \\
Arabidopsis & CAD10598 & EGEQST1002B11.g & $1.00 \mathrm{E}-79$ \\
thaliana & & EGCBSL4281G09.g & $6.00 \mathrm{E}-77$ \\
Triticum aestivum & CAC34012 & EGEQST1002B11.g & $6.00 \mathrm{E}-74$ \\
Spinacia oleracea & BAA96808 & EGEQST1002B11.g & $2.00 \mathrm{E}-70$ \\
\hline
\end{tabular}

identification of several conserved regions of the protoporphyrinogen IX oxidase with lengths ranging from one to thirteen amino acids.

The phylogenetic distance matrix obtained from the amino acid sequences is represented in Figure 3. The least phylogenetic distances in relation to cluster "EGCBSL $4281 \mathrm{G} 09$.g" were 0,272 and 0,274 verified for the species Oryza sativa and Zea mays, repectively. These species were the only two grasses considered in this study and formed a specific branch of the tree. The phylogenetic distance from Oryza sativa to Zea mays was only " 0,105 ". A second branch with short phylogenetic distance $(0,093)$ was produced by the two Solanaceae species (Solanum tuberosum and Nicotiana tabacum). A third branch was formed by Spinacea oleracea (Amaranthacea) and Arabidopsis thaliana (Brassicacea) with a phylogenetic distance of 0,253 between the two species.

Table 3 - Translation frames for the nucleotide sequence of read EGCBSL4281G09.g, e-values, amino acid sequence lengths corresponding to the enzyme protoporphyrinogen IX oxidase (E.C. 1.3.3.4), and identity percentages in relation to the cluster, for different higher plant species.

\begin{tabular}{|c|c|c|c|c|c|}
\hline Species & Frame & g.i. & e-value & Length of sequences ${ }^{(1)}$ & Identity (\%) \\
\hline Arabidopsis thaliana & +2 & 56550711 & $3 e-84$ & 537 & 71 \\
\hline Nicotiana tabacum & +2 & 4105186 & $5 e-72$ & 548 & 64 \\
\hline Sichorium intybus & +2 & 6002912 & $6 e-78$ & 555 & 70 \\
\hline Solanum tuberosum & +2 & 3093410 & $2 \mathrm{e}-70$ & 557 & 61 \\
\hline Spinacea oleracea & +2 & 8648059 & $3 e-75$ & 562 & 70 \\
\hline Oryza sativa & +2 & 34902564 & $8 \mathrm{e}-71$ & 563 & 62 \\
\hline Zea mays & +2 & 6715441 & $4 e-78$ & 535 & 71 \\
\hline
\end{tabular}

\footnotetext{
${ }^{(1)}$ Number of coded amino acids.
} 
The cluster "EGEQST1002B11.g" is a sequence of 804 nucleotides that is consensual in three reads. Frame +3 was used to translate the nucleotide sequences into amino acids. Coding was obtained for a total of 179 amino acids. The alignment of the amino acid sequences is represented in Figure 4. The sequence corresponding to the cluster
"EGEQST1002B11.g" aligned to the end region of the sequences from literature. It was possible to identify several conserved regions in the final part of Protoporphyrinogen IX oxidase. The lengths of the conserved regions ranged from one to seven amino acids.

Table 4 - Translation frames for the nucleotide sequence of cluster EGEQST1002B11.g, e-values, amino acid sequence lengths corresponding to the enzyme protoporphyrinogen IX oxidase (E.C. 1.3.3.4), and identity percentages in relation to the cluster, for different higher plant species.

\begin{tabular}{lccccc}
\hline Species & Frame & g.i. & e-value & Length of sequences $^{(1)}$ & Identity $(\%)$ \\
\hline Arabidopsis thaliana & +3 & 56550711 & $3 \mathrm{e}-78$ & 537 & 89 \\
Nicotiana tabacum & +3 & 4105186 & $6 \mathrm{e}-79$ & 548 & 80 \\
Sichorium intybus & +3 & 6002912 & $5 \mathrm{e}-78$ & 555 & 80 \\
Solanum tuberosum & +3 & 3093410 & $7 \mathrm{e}-79$ & 557 & 81 \\
Spinacea oleracea & +3 & 8648059 & $1 \mathrm{e}-74$ & 562 & 78 \\
Oryza sativa & +3 & 34902564 & $3 \mathrm{e}-79$ & 563 & 80 \\
Zea mays & +3 & 6715441 & $1 \mathrm{e}-78$ & 535 & 81 \\
\hline
\end{tabular}

${ }^{(1)}$ Number of amino acids.

A. thaliana -MELSLLR--P_--TTOSC. intybus MTSLTDVCSLNCCRSWSSLPP-----PVSGGSLTSKNPRYLITYSPAHR---KCNRWRFRCSIAKDSPIT EGCBSL4281G09.g -MAAFATATSAAAAASAA-V- N. tabacum -MTTTPIANHPNIFTHQS---_--SSSP-LAFLNRTSFIPFSSISKRNSVNCNGWRTRCSVAKDYTVP S. tuberosum -MTTTAVANHPSIFTHRSPLPSPSSSSSSPSFLFLNRTNFIPYFSTSKRNSVNCNGWRTRCSVAKDYTVP S. oleracea -MSAMALSSTMALSLPQSSMS--..--LSHCRHNRITILIPSSSLRRR--.--GGSSIRCSTISTSNSA 0.sativa -MAAAAAAMATATSATAAPP Z.mays MVAATATAMATAASPLLN-

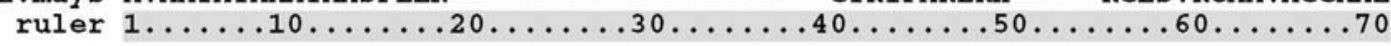

A. thaliana SSKC. intybus PP-...-..-ISNEFNSOPLLDCVIVGAGISGLCIAOALATKHASVSPDVIVTEARDRVGGNISTV EGCBSL4281G09.g QPR--..--AAGGGL-ADCVVVGAGISGLCVAQALATRHRDRAPDVVVTEARDRVGGNITSV N. tabacum SSA--.-- - VDGG--PAAELDCVIVGAGISGLCIAQVMSANYP-_-NLMVTEARDRAGGNITTV S. tuberosum PSE--...-- VDGN--OFPELDCVVVGAGISGLCIAKVISANYP-_- -NLMVTEARDRAGGNITTV S. oleracea AAANYQNKNIGTNGVDGGGGGGGVLDCVIVGGGISGLCIAQALSTKYSNLSTNF IVTEAKDRVGGNITTM 0. sativa APA-----.--APGARVSADCVVVGGGISGLCTAQALATKHG--VGDVLVTEARARPGGNITTA Z.mays APA--..--

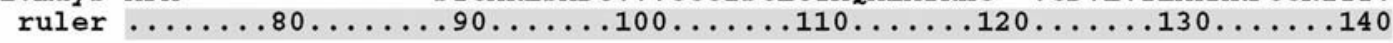

C. intybus ER--DGYLWEEGPNSFQPSDAMLTMVVDSGLKDDLVLGDPTAPRFVLWGGDLKPVPSKPADLPFFDLMSF

EGCBSL4281G09.g ER--DGYLWEEGPNSFQPSDPMLTMAVDSGLKDDLVLGDPNAPRFVLWNGKLRPVPSKPTDLPFFDLMSV N. tabacum ER--DGYLWEEGPNSFQPSDPMLTMAVDCGLKDDLVLGDPNAPRFVLWKGKLRPVPSKLTDLPFFDLMSI

S. tuberosum ER--DGYLWEEGPNSFQPSDPMLTMAVDCGLKDDLVLGDPDAPRFVLWKDKLRPVPGKLTDLPFFDLMSI

S. oleracea EA--DGYLWEEGPNSFOPSDAVLTMAVDSGLKEELVLGDPNSPRFVLWNGKLRPVPSKLTDLPFFDLMSF 0.sativa ERAGEGYLWEEGPNSFQPSDPVLTMAVDSGLKDDLVFGDPNAPRFVLWEGKLRPVPSKPGDLPFFDLMSI $\mathrm{Z}$. mays ERPEEGYLWEEGPNSFQPSDPVLTMAVDSGLKDDLVFGDPNAPRFVLWEGKLRPVPSKPADLPFFDLMSI ruler $\ldots \ldots \ldots 150 \ldots \ldots 160 \ldots \ldots 170 \ldots \ldots 180 \ldots \ldots 190 \ldots \ldots 20 \ldots \ldots$

A. thaliana GGKIRAGFGALGIRPSPP

C. intybus PGKLRAGFGALGFRPSPP

EGCBSL4281G09.g GGKLRAGFGALGIRPPPP N. tabacum PGKLRAGFGAIGLRPSPP

S. tuberosum PGKLRAGFGAIGLRPSPP

S. oleracea PGKIRAGLGALGLRPSPP 0. sativa PGKLRAGLGALGVRAPPPVCVLSPLCILDSLVKFDCAERFRRRFQGREESVEDFVRRNLGAEVFE $\mathrm{Z}$.mays PGKLRAGLGALGIRPPPP ruler $\ldots \ldots 220 \ldots \ldots 230 \ldots \ldots 240 \ldots \ldots 250 \ldots \ldots 260 \ldots \ldots 270 \ldots \ldots$ 
The phylogenetic distance matrix obtained from the amino acid sequences from literature and the cluster "EGE QST1002B11.g" is represented in Figure 5. The maximum phylogenetic distance between the various species was

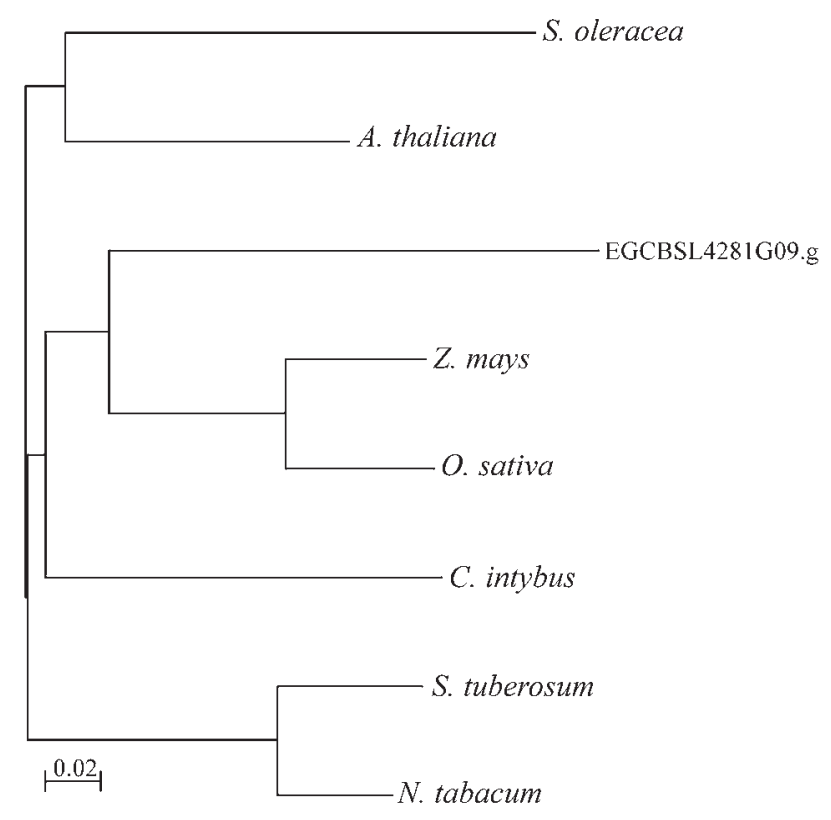

Figure 3 - Graphical representation of the phylogenetic distances obtained from amino acid sequences corresponding to the start region of the enzyme protoporphyrinogen IX oxidase of the studied species.
0.218. Considering the sequences for the final part of the enzyme protoporphyrinogen IX oxidase, the phylogenetic distances from Eucalyptus to the other species ranged from 0.184 (for Zea mays) to 0.218 (for Spinacea oleracea). Two branches formed by Poaceae and Solanaceae species were observed. A third branch enclosed Arabidopsis thaliana and Spinacea oleracea.

The phylogenetic study indicated that the grass species (Zea mays and Oryza sativa) sequences showed higher identity levels, forming an independent branch. These results are important since they are consistent with the available information on the sensitivity of species from different botanical groups to herbicides that act on Protox. Several compounds act preferentially on dicotyledon species. Thus, the existence of a branch in the phylogenetic tree consisting exclusively of grasses could indicate the presence of functional variability in the enzyme and that such variability could be related to a higher or lower sensitivity to herbicides under field conditions. Locating the possible regions and sequences associated with the differential reaction to herbicides could be of great value in establishing breeding programs assisted by genomic tools in the future.

This observation has an even greater relevance when we consider that the level of knowledge about this site of action of herbicides is much lower than that available for nearly all the others. In effect, no information was found in the literature concerning to sequences corresponding to

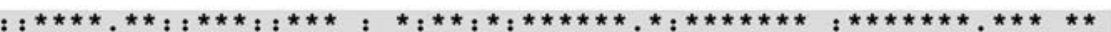

A. thaliana SAANALSKLYYPPVAAVSISYPKEAIRTECLIDGELKGFGQLHPRTQGVETLGTIYSSSLFPNRAPPGRI C. intybus GAADALSKFYYPPVAAVSISYPKDAIRADRLIDGQLKGFGQLHPRSQGVETLGTIYSSSLFPNRAPPGRV EGEQST1002B11.g - - - - KFYYPPVAAVTLSYPKEAIRSERLIDGELKGFGQLHPRSOGVETLGCLYSSSLFPNRAPEGRV N. tabacum AAADALSNFYYPPVGAVTISYPQEAIRDERLVDGELKGFGQLHPRTQGVETLGTIYSSSLFPNRAPKGRV S. tuberosum AAADALSSFYYPPVAAVTISYPQEA IRDERLVDGELKGFGQLHPRSQGVETLGTIYSSSLFPNRAPNGRV

S.oleracea VAAESLSKFHYPPVAAVSLSYPKEAIRSECLIDGELKGFGOLHSRSOGVETLGTIYSSSLFPGRAPPGRT O. sativa DAADALSIFYYPPVAAVTVSYPKEAIRKECLIDGELQGFGQLHPRSQGVETLGTIYSSSLFPNRAPAGRV $\mathrm{Z}$. maYS DAADALSRFYYPPVAAVTVSYPKEAIRKECLIDGELQGFGQLHPRSQGVETLGTIYSSSLFPNRAPDGRV

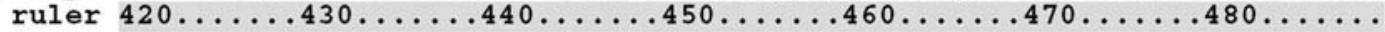

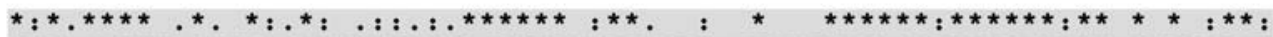

A. thaliana LLLNYIGGSTNTGILSKSEGELVEAVDRDLRKMLIKPNSTDPLKLGVRVWPQAIPQFLVGHFDILDTAKS C. intybus LLLNYIGGATNPEILSKTEGEIVDAVDRDLRTMLIRRDAEDPLTLGVRVWPRAIPQFLIGHYDILDSAKA EGEQST1002B11.g LLLSYIGGATNPGIVSKTPGELVEAVDRDLRKMLINPGAKDPLALGVRVWPQAIPQFLVGHLDHLDSAKA N. tabacum LLLNYIGGAKNPEILSKTESQLVEVVDRDLRKMLIKPKAODPLVVGVRVWPQAIPQFLVGHLDTLSTAKA s. tuberosum LLLNYIGGATNTEIVSKTESQLVEAVDRDLRKMLIKPKAQDPFVTGVRVWPQAIPQFLVGHLDTLGTAKT

S. oleracea LILNYIGGDTNPGILDKTKDELAEAVDRDLRRILINPNAKAPRVLGVRVWPOA IPOFLIGHFDLLDAAKA O. sativa LLLNYIGGSTNTGIVSKTESELVEAVDRDLRKMLINPKAVDPLVLGVRVWPQAIPQFLIGHLDHLEAAKS Z.mays LLLNYIGGATNTGIVSKTESELVEAVDRDLRKMLINSTAVDPLVLGVRVWPQA IPQFLVGHLDLLEAAKA

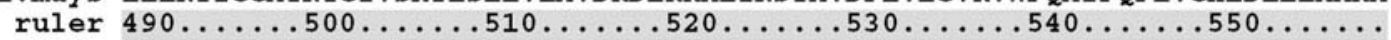

N. tabacum AMNDNGLEGLFLGGNYVSGVALGRCVEGAYEVASEVTGFLSRYAYK

S. tuberosum ALSDNGLDGLFLGGNYVSGVALGRCVEGAYEIASEVTGFLSQYAYK

S. oleracea ALTDGGHKGLFLGGNYVSGVALGRCIEGAYESAAEVVDFLSQYSDK

o. sativa ALGKGGYDGLFLGGNYVAGVALGRCVEGAYESASOISDYLTKYAYK $\mathrm{Z}$. maYs ALDRGGYDGLFLGGNYVAGVALGRCVEGAYESASQISDFLTKYAYK

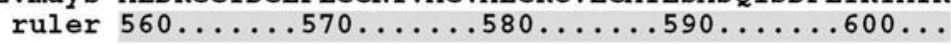




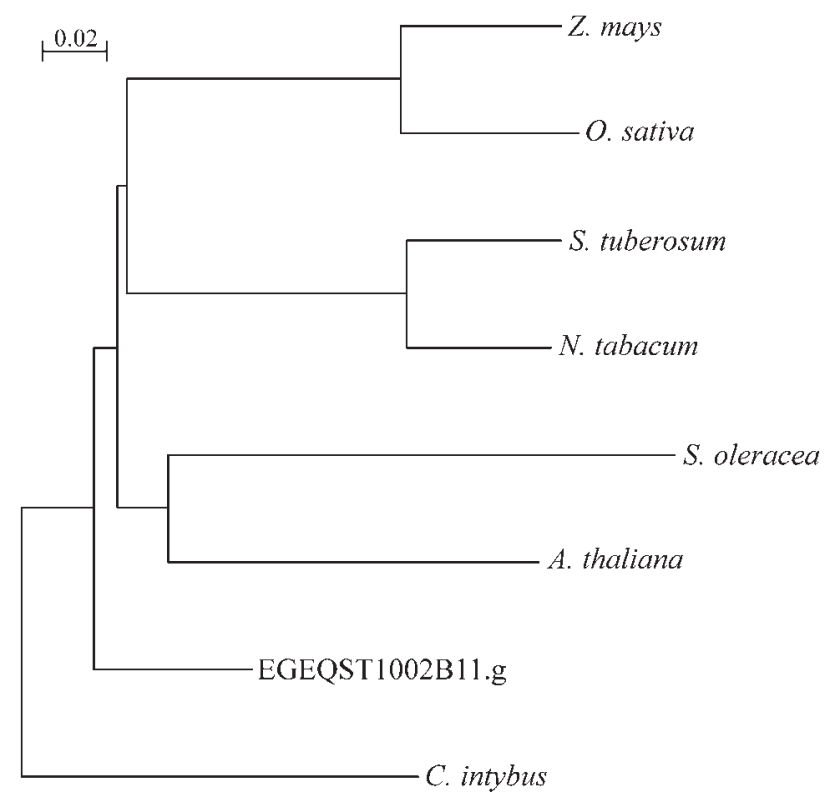

Figure 5 - Graphical representation of the phylogenetic distances obtained from amino acid sequences corresponding to the end region of the enzyme protoporphyrinogen IX oxidase of the studied species.

SNPs or promoters that could be associated with resistance to Protox-inhibiting herbicides.

Results indicated that it is viable to locate preserved regions in the nucleotide sequences corresponding to Protox for developing specific primers to study this enzyme. Such primers are essential to complete the identification of the gene considering that only the start and final regions of protoporphyrinogen IX oxidase from Eucalyptus grandis were already sequenced by FORESTs project. The study of the gene can allow to find promoters and SNPs to induce higher or lower levels of expression of the gene or activity of the enzyme. These, in turn, could be associated with different levels of sensitivity to herbicides, growth (related to chlorophyll accumulation) or tolerance to stresses (related to the accumulation and activity of catalase and peroxidase enzymes).

The potential use of such compounds as oxyfluorfen, sulfentrazone, and other herbicides that act on the Protox enzyme as tools for the development of chemical genetics studies must be pointed out. Such process, described by Blackwell and Zhao (2003), corresponds to the use of chemical compounds to regulate metabolic routes in plants and to predict results that could be obtained by means of genetic alterations to them.

\section{Acknowledgments}

We would to acknowledge RIPASA S.A. Celulose e Papel, DURATEX, Votorantim Celulose e Papel, Suza-
no/Bahia Sul and FAPESP (Fundação de Amparo a Pesquisa do Estado de São Paulo) by the financial support.

\section{References}

Altschul SF, Madden TL, Schaffer AA, Zhang J, Zhang Z, Miller W and Lipman DJ (1997) Grapped BLAST and PSIBLAST: A new generation of protein data base search programs. Nucleic Acids Res 25:3389-3402.

Alves E, Velini ED, Trindade MLB, Catâneo AC, Marino CL, Mori ES, Guerrini IA, Furtado EL and Wilcken CF (2005) Eucaliptus ESTs related to genes for oxidative Stress. Journal of Environmental Science and Health Part B - Pesticides, Food and Agricultural Wastes B40:16-24.

Beale SI and Weinstein JD (1990) Tetrapyrrole metabolism in photosynthetic organism. In: Dailey HA (ed) Biosynthesis of Heme and Chlorophylls. McGraw-Hill, New York, pp 287-391.

Blackwell HE and Zhao Y (2003) Chemical genetic approaches to plant biology. Plant Physiology 133:448-55.

Chaudière J and Ferrari-Iliou R (1999) Intracellular antioxidants: From chemical to biochemical mechanisms. Food and Chem Toxicol 37:949-62.

Dodge AD (1992) Photosynthesis. In: Kikwood RC (ed) Target Sites for Herbicide Action. University of Stranthclyde, Glasgow, pp 1-27.

Grimm B (1998) Novel insight in the control of tetrapyrrole metabolism of higher plants. Curr Opin Plant Biol 1:245250.

Hess FD (1997) Mode of action of glufosinate. In: Herbicide Action Course. Purdue University, West Lafayette, pp 197205.

Hess FD (1993) Herbicide effects on plant structure, physiology, structure, physiology, and biochemistry. In: Altman J (ed) Pesticide Interactions in Crop Production Beneficial and Deleterious Effects. CRC Press, London, 579 pp.

Molina A, Volrath A, Guyer D, Maleck K, Ryals J and Ward E (1999) Inhibition of protoporphyrinogen oxidase expression in Arabidopsis causes a lesion-mimic phenotype that induces systemic acquired resistance. Plant J 17:667-678.

Nelson DL, Cox MM and Lehninger L (2000) Principles of Biochemistry. 3rd ed. Worth Publishers, New York, $1152 \mathrm{pp}$.

Rodrigues BN and Almeida FS (1998) Guia de Herbicidas. Edition of the Authors, Londrina, $648 \mathrm{pp}$.

Watanabe N, Fang-Sik Che, Iwano M, Takayama S, Yoshida S and Isogai A (2001) Dual targeting of spinach protoporphyrinogen oxidase II to mitochondria and chloroplasts by alternative use of in-frame initiation codons. The Journal of Biological Chemistry 273:20447-81.

Weller SC (2002) Photosystem II inhibitors. In: Herbicide Action Course. Purdue University, West Lafayette, pp 127-80.

Weller SC (1997) Photosystem II inhibitors. In: Herbicide Action Course. Purdue University, West Lafayette, pp 101-29.

Wettstein D, Gough S and Kannangara CG (1995) Chlorophyll biosynthesis. Plant Cell 7:1039-1057.

Associate Editor: Helaine Carrer 